\title{
ПРОФИЛАКТИКА ЭКСТРЕМИСТСКИХ НАСТРОЕНИЙ СРЕДИ МОЛОДЕЖИ КАК ФАКТОР СОЦИАЛЬНО-ЭКОНОМИЧЕСКОГО РАЗВИТИЯ РЕГИОНА
}

АНнОтАЦИЯ. В современных условиях проблемы экстремизма являются источником угроз для населения любой страны мира, в том числе и России. В целях противодействия экстремистской деятельности федеральные органы государственной власти в приоритетном порядке осуществляют профилактические меры, направленные на предупреждение экстремистской деятельности. В рамках государственной программы «Укрепление единства российской нации и этнокультурное развитие народов Иркутской области» на 2014-2020 годы Правительством региона осуществляется регулярный мониторинг состояния межнациональных отношений на территории Иркутской области. Особое значение придается изучению экстремистских настроений среди молодежи, поскольку это одна из самых чувствительных категорий населения, играющая большую роль в социально-экономическом развитии региона. В статье определены источники получения информации о проявлениях экстремизма; определено отношение молодежи к проявлениям экстремизма на территории России, Иркутской области и муниципальных образований; проанализировано мнение молодежи относительно причин экстремизма и возможных способах борьбы с ним. На основе полученных данных сформулированы выводы, которые необходимо учитывать при разработке профилактических мер, направленных на противодействие экстремистским настроениям среди молодежи Иркутской области. КЛЮЧЕВЫЕ СЛОВА. Молодежь; экстремистские настроения; профилактика экстремизма; Иркутская область; социально-экономическое развитие.

ИНФОРМАЦИЯ О СТАТЬЕ. Дата поступления 22 октября 2016 г.; дата принятия к печати 10 ноября 2016 г.; дата онлайн-размещения 30 ноября 2016 г.

E. V. Zimina

Baikal State University,

Irkutsk, Russian Federation

\section{PREVENTION OF EXTREMIST MOODS AMONG YOUNG PEOPLE AS A FACTOR OF SOCIO-ECONOMIC DEVELOPMENT OF THE REGION}

\begin{abstract}
In the current context, the problems of extremism are a source of threat for any country of the world, including Russia. In order to counteract the extremist activity, the federal bodies of the public authority, as a priority, take preventive measures aimed at preventing extremist activity. Within the governmental program «Strengthening the unity of the Russian nation and ethno-cultural development of peoples of Irkutsk Oblast for the period of 2014-2020» the Regional Government perform regular monitoring of the international relations state on the territory of Irkutsk Oblast. A special significance is given to studying extremist moods among young people as this is one of the most sensitive population categories that plays a big role in socio-economic development of the region. The article determines the sources of obtaining information about extremism manifestations; determines the relation of young people to extremism manifestations on the territory of Russia, Irkutsk Oblast and municipal entities; analyses the young people's opinion in regard of causes of extremism and possible ways of fighting against it. On the basis of the data obtained, it draws the conclusions to be necessarily considered in developing preventive measures aimed at counteracting extremist moods among the young people of Irkutsk Oblast.
\end{abstract}

(C) Е. В. Зимина, 2016

\section{Baikal Research Journal}

электронный научный журнал Байкальского государственного университета 
KEYWORDS. Young people; extremist moods; prevention of extremism; Irkutsk Oblast; socio-economic development.

ARTICLE INFO. Received October 22, 2016; accepted November 10, 2016; available online November 30, 2016.

Экстремизм в современных условиях стал основным источником угроз для населения нашей страны, в том числе и для жителей Иркутской области. В последние годы проявления экстремизма становятся все опаснее, создают реальную угрозу для безопасности государства. В этой связи государственная политика в сфере борьбы с этими опасными социальными явлениями является важным звеном в системе мер, направленных на обеспечение национальной безопасности России. В широком смысле экстремизм - это приверженность к крайним мерам, действиям, взглядам и решениям. По социальному смыслу экстремизм есть защитная агрессия, направленная против радикальных изменений существующего социального порядка. Он является естественной реакцией различных социальных сил на критические социальные ситуации, формой борьбы с этими критическим ситуациями, направленной на возвращение к докритическому состоянию. Экстремизм по существу есть борьба поставленных в критическую ситуацию социальных групп чрезвычайными средствами и способами за сохранение своего физического существования и культурной идентичности [1, с. 87].

В последнее время распространены попытки напрямую увязать экстремизм с такими проблемами, как рост бедности, социальное неблагополучие, низкий культурный уровень некоторых социальных, этнических и религиозных групп; однако ни исторические примеры, ни современные исследования не подтверждают эту гипотезу. Вместе с тем явления экстремизма и терроризма заметны и хорошо прослеживаются в обществах, вступивших на путь трансформаций, и концентрируются в маргинальных слоях социума, характеризующихся сочетанием традиционных и новых черт культуры, неполным изменением статуса и условий жизни [2, с. 101$]$. Так, в работах Г. И. Авциновой [3, с. 31] и С. А. Эфирова [4, с. 37] под экстремизмом понимался политический радикализм, преимущественно в форме пропагандирования ультраправых идей и взглядов. В русский язык это слово «экстремизм» пришло вместе с другими иноязычными заимствованиями [5, с. 74].

В социологических исследованиях распространение получило понимание экстремизма как системы. Наиболее полным в этом направление является определение предложенное И. И. Ремезовой, которая считает, экстремизм, прежде всего устойчивая определительно-ориентационная система, характерная модель сознания, чьи основные паттерны воспроизводятся в разное время, у разных народов, в разных формах [6, с. 141]. А. И. Бобков в своих работах освещает социально-философские аспекты связи религиозного опыта и этнического самосознания в условиях кризиса национально-цивилизационной идентичности [7].

Многообразие национального и религиозного состава населения Иркутской области, многовековой опыт межкультурного и межрелигиозного взаимодействия, традиции учета потенциала и интересов всех проживающих на ее территории народов, высокий уровень самосознания этнических общностей составляют интеграционный ресурс Иркутской области, определяют состояние и позитивный вектор дальнейшего развития межнациональных отношений в Приангарье, который напрямую влияет на социально-экономическое развитие региона. В соответствии со статьей 5 Федерального закона «О противодействии экстремистской деятельности» от 25 июля 2002 г. № 114-ФЗ в целях противодействия экстремистской деятельности федеральные органы государственной власти, органы государственной власти субъектов Российской Федерации, органы местного самоуправления в

\section{Baikal Research Journal}

электронный научный журнал Байкальского государственного университета 
пределах своей компетенции в приоритетном порядке осуществляют профилактические, в том числе воспитательные, пропагандистские, меры, направленные на предупреждение экстремистской деятельности.

В Иркутской области реализуется государственная программа «Укрепление единства российской нации и этнокультурное развитие народов Иркутской области» на 2014-2020 годы. В рамках данной программы Правительством Иркутской области осуществляется регулярный мониторинг состояния межнациональных (межэтнических) отношений на территории Иркутской области, включающий взаимодействие с региональными управлениями федеральных органов власти (управление Федеральной миграционной службы по Иркутской области, управление Министерства юстиции Российской Федерации по Иркутской области, управление Федеральной службы безопасности Российской Федерации по Иркутской области, главное управление Министерства внутренних дел Российской Федерации по Иркутской области), муниципальными образованиями, общественными национально-культурными объединениями. Вышеуказанная программа включает в себя подпрограмму «Комплексные меры профилактики экстремистских проявлений» на 2014-2020 годы.

Иркутская область подвержена распространению экстремизма, поскольку на ее территории проживает около 130 разных национальностей. Основой для деятельности экстремистских организаций могут являться конфликты, возникающие на межнациональной основе. В связи с этим, очевидно, что молодому поколению необходимо учиться межкультурному взаимодействию. Необходимо проводить ряд профилактических мероприятий среди молодежи, поскольку от того, насколько будет высок уровень толерантности, зависит успешность формирования здорового гражданского общества и в целом социально-экономического развития страны [8, с. 316]. В сложившихся современных условиях лишь с помощью программно-целевого подхода возможна результативная профилактика экстремизма $[9$, с. 99]. Только путем комплексного подхода можно добиться повышения уровня антиэкстремистской защищенности жителей Иркутской области, эффективности управления процессами межнациональных отношений. Криминалистическая характеристика экстремизма дает возможность разработать основные принципы его расследования и разработки профилактики [10, с. 222].

Чтобы профилактические меры по предупреждению экстремистских настроений были результативны, необходимо в постоянном режиме проводить мониторинг по изучению установок молодежи на проявления экстремизма и терроризма.

С целью выявления мнений по экстремистским настроениям в молодежной среде в мае-октябре 2016 г. было проведено социологическое исследование. Генеральную совокупность исследования составила молодежь г. Иркутска и Иркутской области в возрасте от 14 до 30 лет включительно.

Методологией выявления мнений населения являлся метод формализованного интервьюирования респондентов по месту жительства, по заранее разработанной и согласованной программе проведения социологического исследования.

Социологическое исследование проводиться в 15 муниципальных образования Иркутской области. Это: г. Иркутск; Муниципальное образование «Ангарский городской округ»; Зиминское городское муниципальное образование; Муниципальное образование «Балаганский район»; Муниципальное образование «Заларинский район»; Муниципальное образование «Казачинско-Ленский район»; Муниципальное образование «Куйтунский район»; Муниципальное образование «Нижнеилимский район»; Муниципальное образование «Нижнеудинский район»; Муниципальное образование «Тайшетский район»; Усть-Кутское муниципальное образование; Муниципальное образование «Усть-Удинский район»; Черемховское

\section{Baikal Research Journal}


районное муниципальное образование; Муниципальное образование «Нукутский район»; Муниципальное образование «Эхирит-Булагатский район».

Объем и состав выборочной совокупности исследования рассчитывается с учетом распределения населения региона по муниципальным образованиям. Метод формирования выборки - квотный отбор. Квотирование осуществляется для каждого муниципального образования по следующим критериям: пол, возраст, район проживания. Квоты опрашиваемых по полу, возрасту, району проживания представлены ниже.

Общий объем выборки составлял 1000 респондентов, проживающих на территории г. Иркутска (300 респондентов) и муниципальных образований (700 респондентов).

В ходе исследования было опрошено 1 тыс. чел. Иркутской области, из них 49,8 \% женщин и 50,2 \% мужчин. По возрасту респонденты были распределены на три возрастные группы: 14-17 лет $(25,7 \%), 18-24$ года $(46,5 \%), 25-30$ лет $(27,8 \%)$. По сфере деятельности основную часть опрошенных представили студенты вузов $(38,4 \%)$, работающие респонденты $(31,6$ \%) и школьники $(20,0 \%)$. По национальному составу большинство респондентов идентифицируют себя с русскими $(77,4 \%) .7,8 \%$ респондентов указали, что являются бурятами.

Большинство респондентов $(68,5 \%)$ определяют экстремизм как возбуждение социальной, расовой, национальной или религиозной розни. $41,6 \%$ респондентов из числа опрошенных также отнесли к экстремизму "размещение в сети интернет материалов, оскорбляющих личность на почве социальной, религиозной и национальной принадлежности». Стоит отметить, что большое количество информации в интернете делает невозможным контроль за всеми ресурсами сети, что и делает интернет удобной платформой для распространения материалов экстремистского содержания среди пользователей (через социальные сети, чаты, блоги, форумы).

В свою очередь, если проанализировать ответы респондентов через возрастную структуру, можно заметить, что молодые люди в возрасте 14-17 не знакомы с определением экстремизма. Так, большинство понимает под экстремизмом занятия экстремальными видами спорта $(38,2 \%)$ и публичное выражение своего мнения $(33,3 \%)$. У многих опрошенных данный вопрос вызвал затруднения с ответом, несмотря на то, что можно было выбрать несколько вариантов $(32,3$ \% ).

Основную информацию о проявлениях экстремизма респонденты получают через следующие источники: интернет $(75,1 \%$ ) (в последнее время распространяется интернет-экстремизм) [11, с. 33], телевизионные программы $(61,1 \%)$, друзья и знакомые $(21,7 \%)$, печатные издания $(15,6 \%)$ и радиопередачи $(8,9 \%)$.

Респондентам задавался вопрос, касающийся причин распространения экстремизма. По мнению молодежи, основными причинами экстремизма является то, что в России проживает большое количество разных народов, представители которых не всегда находят общий язык $(40,2$ \%) и наиболее распространенный ответ - это «Целенаправленное разжигание представителями экстремистско-настроенных организаций националистической агрессии» $(41,3 \%)$.

Особое внимание в исследовании было уделено изучению мнений респондентов относительно актуальности проблем экстремизма в России, Иркутской области и муниципального образования, в котором они проживают. Большинство респондентов $(40,5 \%)$ отметили, что проблема экстремизма является актуальной для России и скорее актуальной 39,6 \% . Такие цифры, без сомнений, вызывают беспокойство. Что касается ответов на вопрос на сколько актуальны эти проблемы для Иркутской области, то мы можем увидеть немного иную картину. Молодое население муниципальных образований все-таки считают, что проблемы экстремизма «скорее не актуальны» или «не актуальны» для Иркутской области. Это

\section{Baikal Research Journal}

электронный научный журнал Байкальского государственного университета 
можно объяснить тем, что Иркутская область территориально удалена от «проблемных" областей, например, Южного федерального округа, где низкое социально-экономическое развитие округа является причиной, порождающей терроризм и экстремизм в этом регионе.

Из пятнадцати муниципальных образований наибольшую обеспокоенность вызывает Тайшетский район, поскольку 37,5 \% респондентов считают экстремизм достаточно актуальной проблемой для своей территории; также можно выделить Зиминское городское муниципальное образование, где $34,0 \%$ видят проблему экстремизма актуальной и Эхирит-Булагатский район $(32,0 \%)$.

Именно в этих регионах в первую очередь на уровне местных властей должны быть предприняты усилия по предотвращению проявлений экстремизма среди населения и должна быть проведена работа с молодыми людьми. Большинство респондентов отмечает, что экстремизм наиболее распространен в молодежной среде $(52,4 \%)$. С этим нельзя не согласиться, потому что в настоящее время молодежные социальные движения и объединения являются носителями идей, мобильны и слабо мотивированы. Внимание государства к этим вопросам является важной задачей национальной безопасности страны. По мнению респондентов, молодежный экстремизм в России является следствием ряда причин: подверженность чужому влиянию, мнению $(51,1 \%)$; низкий уровень интеллекта $(36,6 \%)$; особенности молодого возраста, стремление изменить мир $(35,0 \%)$; отсутствие правовой, нравственной, духовной культуры $(31,7$ \%). Также дополнительно респондентами были названы такие причины, как коррупция, крайне низкий уровень образования молодежи, отсутствие внимание в кругу семьи.

Таким образом, большинство причин распространения экстремизма молодое поколение относит к социально-психологическим особенностям молодежи, нежели к социально-экономическим или политическим условиям [12, с. 28].

На вопрос о том, происходит ли распространение экстремистских взглядов среди молодежи Иркутской области, 42,3 \% респондентов ответили отрицательно, несмотря на то, что 42,8 \% считают проблему экстремизма в целом актуальной для Иркутской области. Чаще всего, по мнению респондентов, среди молодежи можно встретить экстремистские взгляды и конфликты на национальной (расовой) почве $(55,7 \%)$. Возможно, поэтому абсолютное большинство молодых людей Иркутской области $(53,8$ \%) боятся стать жертвами национальных, расовых конфликтов и террористических актов.

При анализе ответов респондентов на вопрос «Приходилось ли лично Вам сталкиваться с проявлением экстремизма в повседневной жизни (в том числе в отношении Вас лично)?» в разрезе возрастной структуры становится очевидно, что наиболее подвержены проявлениям экстремизма в регионах молодые люди 18-24 лет. Из 24,3 \% респондентов, которые сталкиваются с проявлениями экстремизма в повседневной жизни, большинство $(53,2 \%)$ никак не реагируют на ситуацию и предпочитают ее проигнорировать.

Социально-экономические развитие области напрямую зависят от состояния межнациональных отношений в регионе, которые в свою очередь, могут провоцировать противоправное поведение населения. Большинство молодых людей в целом отмечают толерантное отношение к людям других национальностей $(43,0 \%)$, религий. 50,8 \% респондентов отметили, что религиозность человека не влияет на отношение к нему и допускают, что человек имеет право быть нерелигиозным. Большинство молодых людей не испытывают неприязни по отношению к лицам той или иной национальности $(64,9 \%)$. Неприязнь испытывает лишь $4,4 \%$ респондентов. Таким образом, проблема межэтнической напряженности не является острой для Иркутской области, однако имеет место быть. При достаточной

\section{Baikal Research Journal}


распространенности, по мнению респондентов, молодежного экстремизма в Иркутской области, опрашиваемые выделили следующие его формы: рост преступности и насилия в молодежной среде $(48,1 \%)$, распространение экстремистских идей и взглядов $(47,6$ \%), проявление экстремистских групп, организаций и движений $(39,1 \%)$.

Большинство молодых людей считает, что усиление уголовной ответственности в отношении преступных проявлений экстремизма $(36,8$ \%), активизация работы специальных служб и системы МВД (33,6 \%), а также воспитание молодежи в духе патриотизма $(32,1$ \%) смогут препятствовать распространению идей терроризма, экстремизма и ксенофобии в молодежной среде

С целью выявления национальностей, к которым молодые люди относятся негативно, респондентам был задан дополнительный открытый вопрос с просьбой указать национальности, к которым они испытывают чувство неприязни. Среди таких национальностей были выделены следующие: азербайджанцы, узбеки, цыгане, буряты, дагестанцы, азиаты, арабы, таджики, сирийцы, армяне, башкиры, татары, грузины, чеченцы, кавказская национальность, киргизы, китайцы, тувинцы, украинцы.

Решение проблем экстремизма, по мнению респондентов, в большей степени зависит от каждого человека в отдельности $(45,0 \%)$ и населения в целом $(31,9$ \%). Только общими усилиями всех слоев населения можно решить проблему экстремизма [13].

Несмотря на то, что среди возможных вариантов ответа на вопрос: «От кого, по Вашему мнению, в наибольшей степени зависит решение проблем экстремизма?» были правоохранительные органы, местные органы власти, региональные и федеральные власти, низкий процент респондентов, выбравших эти варианты, свидетельствует о низком уровне доверия молодежи к данным структурам государственной политике в целом по вопросам национальной безопасности в области экстремизма и терроризма.

Обобщив полученные данные можно сделать ряд выводов. Разрабатывая профилактические меры, направленные на противодействие экстремистским настроениям и проявлениям среди молодежи Иркутской области, необходимо учитывать:

1. Молодые люди определяют экстремизм как возбуждение социальной, расовой, национальной или религиозной розни, что свидетельствует об их социальной и нравственной зрелости.

2. Основным источником информации о проявлениях экстремизма для молодежи является интернет. Все реже информационное влияние на молодежь оказывают радиопередачи и печатные издания.

3. $К$ основным причинам экстремизма молодежь относит социально-экономические: многонациональность народов, проживающих на территории России; целенаправленное разжигание представителями экстремистско-настроенных организаций националистической агрессии; пропаганду насилия, национализма, экстремизма в средствах массовой информации.

4. У молодежи Иркутской области преобладает чувство незащищенности от религиозных, национальных конфликтов, террористических актов.

5. В Иркутской области среди всех форм экстремизма наиболее развит национальный. Чаще всего среди молодежи можно встретить экстремистские взгляды и конфликты именно на национальной (расовой) почве.

6. Среди молодежи Иркутской области отмечается низкий уровень доверия. Молодые люди считают, что решение проблем экстремизма в большей степени зависит от каждого человека в отдельности и населения в целом. К правоохранительным органам, местным (муниципальным) органам власти, региональным (об-

\section{Baikal Research Journal}

электронный научный журнал Байкальского государственного университета 
ластным) и федеральные властям среди молодежи Иркутской области отмечается низкий уровень доверия.

В целом, говорить о массовости распространения экстремистских движений, проявлении экстремистских установок и взглядов среди молодежи именно в Иркутской области не приходится. Однако профилактика экстремизма необходима, поскольку молодежь - это одна из самых чувствительных и уязвимых категорий населения, играющая большую роль в социально-экономическом развитии региона.

\section{Список использованной литературы}

1. Яхьяев М. Я. Экстремизм: методологические подходы к исследованию проблем [Электронный ресурс] / М. Я. Яхьяев // Экстремизм. Ru. - 2010. - 8 ноября. - Режим доступа: http://www.ekstremizm.ru/publikacii/izuchenie-i-prognozirovanie/item/616-.

2. Егоров М. И. Молодежный экстремизм как социальное явление в условиях постиндустриального общества / М. И. Егоров, Я. А. Маргулян // Современные проблемы науки и образования. - 2012. - № 5. - С. 101-102.

3. Авцинова Г. И. Политический радикализм в России: концептуальные подходы к понятию и пути нейтрализации / Г. И. Авцинова // Вестник Московского университета. Сep. 12 , Политические науки. - 1995. - № 3. - С. 31 .

4. Эфиров С. А. Опасность радикализма / С. А. Эфиров // Политические исследования. - 1994. - № 2. - С. 37.

5. Загоровская О. В. Об иноязычных заимствованиях в политической лексике русского языка / О. В. Загоровская, С. А. Есмаеел // Вестник Воронежского государственного университета. Сер. Лингвистика и межкультурная коммуникация. - 2008. - № 3. - С. 74-82.

6. Ремезова И. И. Экстрим: междисциплинарное философское исследование причин, форм и паттернов экстремистского сознания / И. И. Ремезова, В. И. Красиков. - М. : Водолей, 2006. - 496 с.

7. Бобков А. И. Религиозный опыт и этническое самосознание в условиях кризиса национально-цивилизационной идентичности : монография / А. И. Бобков. - Иркутск : Изд-во Иркут. гос. ун-та, 2013. - 287 с.

8. Юмашева Т. А. Профилактика экстремизма среди молодежи / Т. А. Юмашева // Организованная преступность и коррупция: результаты криминолого-социологических исследований. - Саратов : Сателлит, 2010. - Вып. 5. - С. 316-317.

9. Мусаелян М. Ф. Профилактика экстремизма - важнейшее направление противодействия экстремизму в Российской Федерации / М. Ф. Мусаелян // Адвокат. - 2009. № 7. - C. 99 .

10. Кряжев В. С. Значение криминалистической характеристики преступлений террористической и экстремистской направленности в методике их расследования / В. С. Кряжев // Сибирские уголовно-процессуальные и криминалистические чтения. - 2014. Вып. 1 (5). - C. 221-226.

11. Руденко О. Ю. Киберэкстремизм в молодежной среде / О. Ю. Руденко // Практика коммуникативного поведения в социально-гуманитарных исследованиях : материалы IV Междунар. науч.-практ. конф., 1-2 дек. 2013 г. - Прага : Vědecko vydavatelskě centrum «Sociosfěra-CZ», 2013. - C. 33-35.

12. Юрасова Е. Н. Психологические особенности лиц, склонных к экстремизму, терроризму и ксенофобии / Е. Н. Юрасова // Юридическая психология. - 2008. - № 4. - С. 28.

13. Бидова Б. Б. Специально-криминологическое противодействие молодежному экстремизму / Б. Б. Бидова // Молодой ученый. - 2012. - № 11. - С. 287-289.

\section{References}

1. Yakhyaev M. Ya. Extremism: methodological approaches to investigating problems. $E k-$ stremizm. $R u, 2012$, November 8. Available at: http://www.ekstremizm.ru/publikacii/izuchenie-i-prognozirovanie/item/616-. (In Russian).

2. Egorov M. I., Margulyan Ya. A. Youth extremism as a social phenomenon in terms of the postindustrial society. Sovremennye problemy nauki i obrazovaniya = Recent Developments in Science and Education, 2012, no. 5, pp. 101-102. (In Russian).

\section{Baikal Research Journal}


3. Avtsinova G. I. Political radicalism in Russia: conceptual approaches to the notion and ways of neutralization. Vestnik Moskovskogo universiteta. Seriya 12, Politicheskie nauki= Moscow University Bulletin. Series 12, Political Science, 1995, no. 3, p. 31. (In Russian).

4. Efirov S. A. Danger of radicalism. Polis. Politicheskie issledovaniya = Polis. Political Studies, 1994, no. 2, p. 37. (In Russian).

5. Zagorovskaya O. V., Esmaeyel S. A. On foreign borrowings in political vocabulary of the Russian language of. Vestnik Voronezhskogo gosudarstvennogo universi-teta. Seriya: Seriya Lingvistika $i$ mezhkul'turnaya kommunikatsiya = Proceedings of Voronezh State University. Series: Linguistics and Intercultural Communication, 2008, no. 3, pp. 74-82. (In Russian).

6. Remezova I. I. Krasikov V. I. Ekstrim: mezhdistsiplinarnoe filosofskoe issledovanie prichin, form i patternov ekstremistskogo soznaniya [The extreme: inter-disciplinary philosophical investigation of causes, forma and patterns of extremist consciousness]. Moscow, Vodolei Publ., 2006. 496 p.

7. Bobkov A. I. Religioznyi opyt i etnicheskoe samosoznanie $v$ usloviyakh krizisa natsional'no-tsivilizatsionnoi identichnosti [Religious experience and ethnic self-consciousness in terms of crisis of national and civilized identity]. Irkutsk State University Publ., 2013. 287 p.

8. Yumasheva T. A. Extremism prevention among young people. Organizo-vannaya prestupnost' $i$ korruptsiya: rezul'taty kriminologo-sotsiologicheskikh issledovanii [Organized criminality and corruption: results of criminological and sociological studies]. Saratov, Satellit Publ., 2010, iss. 5, pp. 316-317. (In Russian).

9. Musayelyan M. F. Extremism prevention is the most important direction of counteracting extremism in the Russian Federation. Advokat = Lawyer, 2009, no. 7, p. 99. (In Russian).

10. Kryazhev V. S. The value of the forensic characteristics of the crimes of terrorism and extremism in the methods of their investigation. Sibirskie ugolovno-protsessual'nye $i$ kriminalisticheskie chteniya = Siberian Criminal Procedure and Forensic Reading. 2014, iss. 1, pp. 221-226. (In Russian).

11. Rudenko O. Yu. Cyber-extremism among young people. Praktika kom-munikativnogo povedeniya $v$ sotsial'no-gumanitarnykh issledovaniyakh. Materialy IV Mezhdunarodnoi nauchno-prakticheskoi konferentsii, 1-2 dekabrya $2013 \mathrm{~g}$. [Practice of communicative behavior in socio-humanitarian studies. Materials of the 4 th International Research Conference, December 1-2, 2013]. Praga, Vědecko vydavatelskě centrum «Sociosfěra-CZ» Publ., 2013, pp. 33-35. (In Russian).

12. Yurasova E. Psychological features of persons apt to extremism, terrorism and xenophobia. Yuridicheskaya psikhologiya = Juridical Psychology, 2008, no. 4, p. 28. (In Russian).

13. Bidova B. B. Special criminological counteraction to youth extremism. Molodoi uchenyi $=$ Young Scientist, 2012, no. 11, pp. 287-289. (In Russian).

\section{Информация об авторе}

Зилина Екатерина Викторовна - кандидат социологических наук, доцент, кафедра социальной и экономической психологии, социологии и социальной работы, Байкальский государственный университет, 664003, г. Иркутск, ул. Ленина, 11, e-mail: Katerinovna@list.ru.

\section{Author}

Ekaterina V. Zimina - PhD in Sociology, Associate Professor, Chair of Social and Economic Psychology, Sociology and Social Work, Baikal State University, 11 Lenin St., 664003, Irkutsk, Russian Federation; e-mail: Katerinovna@list.ru.

\section{Библиографическое описание статьи}

Зимина Е. В. Профилактика экстремистских настроений среди молодежи как фактор социально-экономического развития региона / Е. В. Зимина // Baikal Research Journal. 2016. — T. 7, № 6. — DOI: 10.17150/2411-6262.2016.7(6).15.

\section{Reference to article}

Zimina E. V. Prevention of extremist moods among young people as a factor of socioeconomic development of the region. Baikal Research Journal, 2016, vol. 7, no. 6. DOI: 10.17150/2411-6262.2016.7(6).15. (In Russian).

\section{Baikal Research Journal}

